\title{
Personalidade Gastronômica e Destinos Turísticos: avaliação dos canais de comunicação na projeção dos atrativos gastronômicos no nordeste brasileiro
}

\begin{abstract}
Gastronomic Personality and Tourism Destinations: communication channels evaluation in the gastronomic attractions projection in Brazilian Northeastern
\end{abstract}

\author{
Personalidad Gastronómica y Destinos Turísticos: \\ evaluación de los canales de comunicación en la proyección de las atracciones culinarias \\ en el noreste de Brasil
}

Ernani Coelho Neto ${ }^{1}$

Leandro Urias ${ }^{2}$

\section{Resumo}

O artigo apresenta uma análise dos canais de comunicação mais empregados na divulgação das tradições culinárias de nove capitais do nordeste do Brasil. A avaliação foi feita com base em dados levantados pelo Projeto Caminhos do Sabor, iniciativa conjunta da Associação Brasileira de Bares e Restaurantes e Ministério do Turismo, a partir de entrevistas com visitantes em cada uma das cidades. Os dados revelam que a comunicação "boca-a-boca" é o principal vetor de disseminação de informações e impressões sobre a culinária nordestina.

Palavras-chave: turismo; gastronomia; culinária; imagem territorial; canais de comunicação.

\begin{abstract}
This article presents an analysis of the most used communications channels to disseminate the culinary traditions of nine capitals of the Northeast of Brazil. The evaluation was based on data collected by the Projeto Caminhos do Sabor (Paths of Flavor Project) - a joint initiative of the Associação Brasileira de Bares e Restaurantes (Bars and Restaurants Brazilian Association) and the Ministério do Turismo (Ministry of Tourism) - through interviews which were made with the visitors of each one of the cities. The data show that the statement "word-of-mouth" is the main dissemination vector of information and views of the Northeastern culinary.
\end{abstract}

Keywords: tourism; gastronomy; culinary; territorial image; communication channels.

\section{Resumen}

El artículo presenta un análisis de los canales de comunicación más empleados en la divulgación de las tradiciones culinarias de las nueve ciudades del noreste de Brasil. La evaluación se basó en los datos recopilados por el Proyecto Caminos del Sabor, una iniciativa conjunta de la Asociación Brasileña de Bares y Restaurantes y el Ministerio de Turismo,

\footnotetext{
${ }^{1}$ Doutor em Comunicação e Cultura Contemporâneas, Professor Adjunto da Escola de Administração da Universidade Federal da Bahia. E-mail: ecneto@ufba.br

${ }^{2}$ Leandro Urias - Engenheiro de Alimentos, sócio da Insight Consultoria e Projetos, fez parte da Coordenação Nacional do Projeto Caminhos do Sabor. E-mail: lurias@incp.com.br.
} 
sobre la base de entrevistas con los visitantes en cada ciudad. Los datos revelan que la declaración de "boca en boca" es el principal vector de diseminación de información y opiniones sobre la cocina del noreste.

Palabras clave: turismo; gastronomia; cocina; imagen territorial; vías de comunicación.

\section{Introdução}

O turismo é uma atividade simbólica. A relação entre o viajante e o lugar realiza seu sentido no plano da experiência. No final das contas, são as sensações e impressões que restam ancoradas na subjetividade. O lugar se constrói no imaginário, lá se converte em valor afetivo e registro duradouro na memória. O processo é complexo. Depende, entre outras coisas, das expectativas, da qualidade dos serviços prestados, do nível de contato com as culturas locais, das características do destino escolhido. Os significados, inclusive, costumam se adiantar ao deslocamento. Antes de viajar é preciso escolher para onde ir. A seleção de um destino não pode acontecer sem informação ou julgamento prévio. Mais uma vez o imaterial conta, e, dentre muitos aspectos, a imagem do lugar é poderosa força de mobilização. O chamariz certo faz o lugar parecer atraente, merecedor de atenção e de desejo.

Um destino turístico tem múltiplas dimensões e sua imagem tende a representá-las de alguma maneira. Algumas dimensões contribuem para a atratividade. Outras afastam os visitantes. Para muitos lugares a comida - e o universo cultural ao seu redor - representa um importante componente de suas imagens. Apesar disso, mesmo nesses casos, sabe-se pouco sobre a forma como a informação sobre a comida é difundida a ponto de originar e sustentar uma personalidade gastronômica. A proposta desse trabalho é, a partir da reflexão teórica e da análise de dados de campo, refletir a respeito do papel da gastronomia e da culinária na imagem territorial de destinos turísticos e, em seguida, acerca dos canais de comunicação que são empregados na construção na familiarização do turista com os hábitos e tradições alimentares locais.

Em busca de respostas, estruturamos um roteiro de discussão que se apóia na literatura sobre o tema e em dados obtidos através de um conjunto de pesquisas realizadas no âmbito do Projeto Caminhos do Sabor - a União Faz o Destino. O Projeto, que teve início em 2008 e que deve ser concluído em 2011, é uma iniciativa da Associação Brasileira de Bares e 
Restaurantes (ABRASEL) e do Ministério do Turismo (MTur). Seu objetivo é ajudar os 65 destinos indutores do turismo brasileiro a aumentar sua competitividade através da gastronomia e da culinária. Graças aos dados reunidos, foi possível estabelecer uma base de comparação que envolve as capitais dos estados do nordeste brasileiro.

A estrutura do artigo contempla mais quatro seções. Na seção seguinte - Imagem e reputação - apresentamos uma análise conceitual do fenômeno da imagem e da reputação, assim como, algumas implicações para o turismo. Na terceira seção - Gastronomia e culinária como atrativo turístico - procuramos estabelecer os vínculos entre a personalidade gastronômica e a imagem territorial. A seção quatro - Canais de comunicação e divulgação da culinária local contém a análise dos dados quantitativos. Por fim, a seção Considerações finais é dedicada às implicações suscitadas pelos argumentos e análises apresentados.

\section{Imagem como Fenômeno de Comunicação}

O estudo da imagem e da reputação como fenômeno de comunicação é um empreendimento diversificado. O tema interessa a diferentes campos do saber. Há literatura sobre o assunto oriunda das áreas da administração, comunicação, turismo, psicologia, sociologia e artes visuais. Por um lado, muitas abordagens dificultam a formação de um quadro teórico integrado e exigem a convivência de proposições conflitantes. Em contrapartida, diversidade significa vias alternativas de investigação e um repertório teórico mais amplo. Assumindo esse fato, para amparar a discussão em curso selecionamos contribuições de matizes diferentes, mas que no conjunto representam e explicam características mais presentes nos estudos sobre a imagem.

A imagem pode ser conceituada de maneiras diferentes. Ratier (2002), autor interessado no viés corporativo da questão, adota a definição de Leclaire (1992): “a imagem pode ser igualmente definida como a representação psíquica e mental da percepção de um objeto ou de um evento, suscetível de subsistir através do espaço e do tempo, e de ser recriada por evocação" (p. 01). A principal vantagem desse conceito é que ele pode ser empregado para qualquer tipo de objeto. Virtualmente tudo é passível de representação e pode ser reduzido a um esquema mental. Não importa se nos referimos a uma pessoa, uma empresa ou a um lugar. 
Implícito está a ideia de que o objeto precisa ser individualizável, ou seja, possuir contornos mais ou menos singulares que permitam fazer contraste em relação ao seu contexto. A definição estabelece também uma condição temporal para a caracterização da imagem. Como fenômeno, a imagem só existe caso perdure e, por conseqüência, produza memória.

Neves (2003), no entanto, reflete que a imagem é uma manifestação instável. Portanto, preservá-la intacta no tempo raramente é uma opção realista. A imagem é formada através de um processo de agregação e depuração, no qual informações favoráveis e desfavoráveis - de acordo com o referencial do indivíduo - interagem para formar uma impressão geral. $\mathrm{O}$ resultado advém do balanço entre o que parece bom e o que parece ruim. Mesmo quando uma empresa goza de boa reputação ou imagem atraente, a percepção associada a elas não é inteiramente positiva. Quanto maior o volume de atributos positivos percebidos, melhor a imagem da organização. O autor reforça a idéia de que a imagem pode se modificar com rapidez. A qualquer momento novas informações podem desajustar um equilíbrio de percepções bem-sucedido. Esse ponto de vista suscita a questão do risco de imagem. Lidar com algo tão sensível envolve esforços para antecipar problemas e proteger o investimento simbólico realizado.

A definição Leclaire (1992), como outras semelhantes, destaca o papel da percepção na explicação da imagem. Stanton et al. (1994) ${ }^{3}$ afirmam que a percepção envolve um conjunto de etapas. Entre elas a coleta, organização, interpretação e associação de significados proveniente de estímulos captados pelos cinco sentidos. As impressões atribuídas dependem das características do objeto e da experiência do observador. Quando informações são captadas pelos sentidos, impressões armazenadas são evocadas e influenciam as interpretações. Novas informações, como o lançamento de um produto, por exemplo, contribuem para a produção de sucessivas impressões, modificando as interpretações originais.

É notório que as propriedades atribuídas a um objeto nem sempre encontram correspondência em características objetivas. Ainda assim, as pessoas lidam com suas percepções como se fossem verdadeiras. A imagem, seja uma representação fiel ou não do objeto, tende a ser percebida pelo indivíduo como uma realidade concreta (NEVES, 2003). Argumentando na

\footnotetext{
${ }^{3}$ apud Viriyavidhayavongs \& Tothmontree (2002).
} 
mesma direção Christie (2002) comenta os resultados da pesquisa de Staw \& Epstein (2000) que indicam que líderes que fazem uso de técnicas administrativas consideradas modernas e recentes são percebidos como mais competentes a despeito do seu desempenho objetivo. Até quando tais técnicas não são empregadas de forma consistente, ou mesmo quando sequer são empregadas, a associação é suficiente para melhorar a imagem do líder e da empresa.

Décaundin (1999), mais um dos autores examinados por Ratier (2002), agrega outros elementos à questão. A imagem é um conjunto de representações sobre indivíduos, grupos, organizações, objetos e símbolos (marcas, por exemplo) que pode assumir um caráter racional ou afetivo. Como fenômeno, suas características marcantes são as seguintes: (1) a imagem é uma construção simbólica; (2) seu processo de formação depende dos fluxos de comunicação que se estabelecem entre a organização e os diversos públicos; (3) embora não se trate de um fenômeno totalmente sob o controle, algum nível de intencionalidade está sempre presente no desenvolvimento da imagem; (4) o público tem uma participação ativa na atribuição dos significados que a compõem.

Noções semelhantes podem ser encontradas nos estudos sobre a imagem dos destinos turísticos. Rashid \& Ismail (2008), numa análise sobre a literatura especializada, revelam que o tema está entre os mais estudados no campo do turismo ao mesmo tempo em que persiste uma enorme ambigüidade nas formas de tratar a questão. As pesquisas iniciais enquadram a imagem como uma representação do lugar transportada para a mente do turista em potencial. A análise das autoras evidencia a proximidade entre a literatura gerencial e do turismo. A preocupação é dominar o fenômeno com vistas a facilitar o processo de gestão. Em ambos os contextos, a imagem é um ativo que precisa ser gerenciado. Daí a fácil transferência de técnicas e esquemas interpretativos entre os dois campos.

O trabalho de Baloglu e McCleary (1999) merece uma menção especial. Os autores, com base na literatura disponível, sistematizaram um modelo de como a imagem dos destinos turísticos é formada. Mesmo sem se afastarem dos esquemas conceituais mais empregados na análise do fenômeno, a contribuição dos autores é rica em função do uso de dados empíricos. A proposta parte da decomposição usual do fenômeno nos seus processos informacional e emocional. A imagem geral, ou a representação final do destino turístico, é produto da 
interação entre dois vetores de análise: o cognitivo (perceptual/cognitive evaluation) e o afetivo (affective evaluation).

A avaliação cognitiva relaciona-se com as crenças e/ou o conhecimento que um indivíduo acumula sobre o destino turístico. Já a avaliação afetiva diz respeito ao conjunto de sentimentos associados ao lugar. A separação entre os dois extremos exala certa artificialidade, no entanto, o procedimento tem méritos pedagógicos ao destacar e chamar atenção para algumas características. Ao buscar validar o modelo através de dados empíricos, os autores concluem que a avaliação cognitiva é influenciada pela variedade, volume e tipo das fontes de informação disponíveis e pela idade e nível educacional dos turistas. Esses mesmos atributos, mais as motivações dos viajantes influenciam a formação dos vínculos afetivos com o lugar.

Para a discussão que estamos encaminhando interessa a noção de ordem e sequência presente no raciocínio. Ao separar os dois processos de avaliação, mesmo considerando a inter-relação entre ambos, fica mais ou menos evidente que a avaliação afetiva só pode ocorrer depois que de algum nível de avaliação cognitiva. Não pode haver associação de sentimentos para com um objeto se não há qualquer estímulo anterior sobre a qual reagir. Assumindo que os vínculos emocionais positivos reforçam o desejo sobre os destinos, a circulação da informação torna-se uma condição necessária e indispensável para a formação de uma imagem eficaz.

Com alguns ajustes, todas as considerações apresentadas até aqui se aplicam à questão da imagem do território. Entendemos a imagem territorial como o conjunto de impressões e associações afetivas e cognitivas que representam para um público específico as características gerais - humanas e naturais - de um espaço geográfico. Esse espaço pode se confundir com um bairro, uma cidade, um conjunto de cidades, estados ou países. Portanto, trabalhamos com a noção de que qualquer território ou partição dele que, numa relação com um público específico, seja capaz de sustentar uma impressão de singularidade é portador de uma imagem territorial.

Gaio e Goveia (2007) desdobram a questão da seguinte forma; “As cidades/regiões possuem identidades com atributos patrimoniais, econômicos, tecnológicos, relacionais, sociais e simbólicos que constituem a base dos processos de construção de imagem dos 
territórios e da marca, através da sua dimensão funcional e simbólica, tem a capacidade de consubstanciar e valorizar essa identidade promovendo identificação e envolvimento com os públicos e simultaneamente distinguindo-a de territórios concorrentes” (p. 30).

A imagem territorial, seguindo o caminho proposto pelos autores, é o agregado de projeções de muitas "sub-imagens" que se relacionam com públicos diferentes, mas que se ancora em alguns traços gerais partilhados pela maioria dos interlocutores do território.

\section{Gastronomia e Culinária como Atrativo Turístico}

Chegamos, então, à seguinte constatação: a imagem do território é um agregado de informações, crenças, impressões afetivas e esquemas mentais que representam as características marcantes do lugar. É claro que a construção da imagem não resulta num todo sempre homogêneo ou uniforme. Levando em conta a complexidade do processo, é necessário aceitar a polifonia que caracteriza sua constituição e compreender a natureza subjetiva das instâncias de interpretação das pessoas que entram em contato com o território.

O agregado carrega indícios de naturezas diversas. Uma cidade como São Paulo projeta muitas características de imagem ao mesmo tempo - grande metrópole, centro cultural, sede das grandes indústrias, rica vida noturna etc. Salvador é a lugar do carnaval e da juventude e, igualmente, a terra das 365 igrejas. Cada parte do conjunto afeta de forma mais intensa um perfil específico de observador e, também, o todo - a imagem geral - se relaciona de maneira especial com a projeção de cada uma das partes.

Do ponto de vista do turista, a gastronomia e a culinária estão sempre presentes na imagem territorial. Isso acontece porque a produção da comida - e de seus significados - é um saberfazer profundamente disseminado na vida social e é resultado de longa trajetória de maturação. Murta et al. (2010) traduzem esse ponto de vista da maneira seguinte: "Entendemos que as características e os significados da alimentação são delineadores da historicidade dos lugares ou identificadores de territórios, como brevemente anunciado no referencial teórico" ( $\mathrm{p}$ 51). O valor e a importância simbólica da comida na imagem territorial podem ser menores num lugar quando comparado com outro. Contudo, é 
impossível buscar um território sem esbarrar nos seus hábitos e ofertas alimentares. Um contato inevitavelmente convertido em crenças, impressões e reações emocionais.

Não por acaso, é comum encontrar trabalhos focados na contribuição da gastronomia e da culinária na atratividade dos destinos turísticos (CRISTOVÃO ET AL., 2008; GRBAC \& MILOHANOVIĆ, 2008; KRAUSE, 2007; OLIVEIRA, 2007; KARIM, 2006; CORNER, 2006; FERNÁNDEZ \& AGRELO, 2003; RAND ET AL., 2003). O turismo gastronômico vem conquistado autonomia como modalidade e como objeto de estudo. Numa variação do conceito de Hall \& Sharples (2003), trata-se do deslocamento cuja principal motivação reside na experimentação ou desfrute dos atributos relacionados à produção de alimentos e a cultura culinária local (visitação a produtores de alimentos, festivais culinários, restaurantes, etc). Alguns estudos correlacionam o turista gastronômico a um perfil de renda elevada, alto padrão educacional, disposição para gastar, e em busca de acomodações e serviços mais sofisticados (OLIVEIRA, 2007; MICHAELL \& HALL, 2003).

A força da gastronomia e da culinária na imagem de um lugar é produto da interação de dois elementos. Em primeiro lugar, o interesse dos públicos que compõem os principais mercados emissores do destino nas experiências gastronômicas. Quanto maior a parcela de turistas gastronômicos no total de visitantes, tanto maior a contribuição da comida na imagem do local. Em segundo lugar, na capacidade da culinária e dos serviços de alimentação do destino mostrarem-se atraentes na perspectiva do visitante. Por exemplo, tradições que se utilizam de ingredientes muito "exóticos" - do ponto de vista do turista, evidentemente - ou em conflito com a cultura de origem dos viajantes, podem resultar em estranheza e repulsa ao invés de incentivar atitudes positivas ${ }^{4}$.

Embora não se refira diretamente à análise do turismo, a discussão de Stiles et al. (2010) lança luz sobre o processo de criação do valor simbólico da comida. Trata-se, antes de tudo, de um esforço de construção de narrativas, calcado em reivindicações de autoria e de autenticidade. A questão da autoria é bastante óbvia. É preciso estabelecer uma impressão de domínio sobre o saber, as habilidades, as tradições, os ingredientes, ou sobre todos ao mesmo tempo. O raciocínio se aplica à discussão em curso da seguinte forma: se um tipo de comida pode ser

\footnotetext{
${ }^{4}$ Para uma análise dos contextos e peculiaridades da imagem gastronômica e culinária ver Coelho Neto \& Azevedo (2010).
} 
encontrado em muitos destinos, sem restrições ou variações importantes no que diz respeito à qualidade do produto ou da experiência alimentar, projetando uma impressão de comida "globalizada" ou "padronizada", as oportunidades para o uso de seus componentes de imagem como vantagem competitiva são limitadas. A autoria pode ser demarcada através dos talentos individuais - um chef famoso que divulga a comida do lugar - através de traços culturais associados ao território, ou por características específicas do meio ambiente. O terroir ${ }^{5}$, por exemplo, pode ser entendido como uma reivindicação de autoria. A transformação do "sabor" do lugar em atrativo turístico ao vincular um tipo de produção ao território. Como o vínculo é carregado de elementos simbólicos, é difícil reproduzir a experiência em outros contextos.

Sobre a autenticidade, os autores escrevem que a comida é um conjunto de relações sociais e ambientais. Das relações emergem significados que reforçam e são reforçados pelos apelos de autoria. As narrativas de autenticidade buscam sinalizar que a comida representada é produzida, armazenada e distribuída dentro de relações apropriadas. Tais narrativas apelam, embora o mecanismo não esteja explícito no texto, para as conexões simbólicas que as pessoas desenvolvem com a comida durante suas vidas e reforçam aspectos desejáveis associados a ela. Os produtos da fazenda, por exemplo, que evocam pureza e qualidade. Trazendo a questão para o turismo, autenticidade representa uma manifestação verdadeira, diferente do modelo da indústria cultural ou do entretenimento, portanto, rico em essência.

No que diz respeito ao território, o principal efeito de narrativas bem-sucedidas de autoria e de autenticidade da culinária e gastronomia é a singularidade. Ser singular é importante porque explicita a distância conceitual e simbólica de um lugar para o outro. Se a singularidade está baseada em atributos desejáveis, os ganhos de competitividade são consideráveis. A comida, dada a grande diversidade de culturas e tradições alimentares, é fonte importante e freqüente de singularidade. Bem trabalhada, as diferenças e peculiaridades do local podem ser convertidas numa personalidade gastronômica. Ou seja, a imagem projetada sobre atributos da cultura culinária e da oferta gastronômica, ancorada nos valores e na cultura do lugar, que reforça o caráter especial e único de um destino turístico (COELHO NETO E AZEVEDO, 2010).

\footnotetext{
${ }^{5}$ Para uma discussão sobre o tema ver Dória (2009).
} 
Para a maioria dos lugares, o que acaba se fixando como personalidade gastronômica é, em geral, resultado de um processo espontâneo. Mas a profissionalização da gestão do turismo em curso no mundo inteiro - e o recrudescimento da competição entre os lugares por rescursos e turistas tendem a modificar essa situação nos próximos anos. Rand et al. (2003), por exemplo, após estudar vários destinos na África do Sul sugerem algumas providências para aproveitar o potencial das culinárias locais no marketing dos destinos turísticos. São elas: (1) a criação de um sentimento de orgulho da comida local; (2) o desenvolvimento de um sistema de identificação de origem dos produtos vinculados ao destino e de uma identidade de marca; (3) estímulo ao uso no setor de alimentação fora do lar de produtos produzidos no lugar.

Tentar gerenciar a personalidade gastronômica de um lugar pode ser uma tarefa desafiadora. Afinal, temos pouco conhecimento e experiências acumuladas nesse sentido. Contudo, não é uma preocupação descabida. Como ocorre com qualquer tipo de manifestação de imagem, o valor e os significados associados a um território podem sofrer transformações importantes (ver NEVES, 2003, já citado). Steinberger (2010), por exemplo, realizou um extenso levantamento da aparente "decadência" da culinária francesa e da perda de protagonismo dessa tradição para outras propostas emergentes como a contemporânea cozinha espanhola. A atratividade da personalidade gastronômica é influenciada por modismos, mudanças e arranjos entre os movimentos sociais em torno da comida.

\section{Canais de Comunicação e Divulgação da Culinária Local}

A representação das tradições, dos talentos e das inovações culinárias de um lugar na literatura, na televisão, no cinema, em revistas e outras mídias, tem o poder de torná-las familiares para um grande contingente de pessoas ao mesmo tempo. Lamentavelmente, poucos destinos contam com a boa vontade dos meios de comunicação e de produtores culturais em geral. Por essa razão, a divulgação consciente e planejada da cozinha local e regional, de seus ingredientes e produtos típicos, dos bares, dos restaurantes e de seus chefs é certamente o meio mais adequado para fortalecer o valor de imagem de um patrimônio culinário e gastronômico. Poucos destinos no Brasil, no entanto, podem afirmar que mantêm políticas ativas de promoção voltadas para o turismo gastronômico. 
Seja por um golpe de sorte ou fruto de um trabalho consciente e planejado, a capacidade de sensibilizar o público alvo e influenciá-lo através da personalidade gastronômica só pode ocorrer num ambiente que estimula um mínimo de circulação de informação e que consolida canais de comunicação entre turistas e o território. Como vimos anteriormente em Baloglu e McCleary (1999), a informação é a etapa inicial do processo de formação da imagem (avaliação cognitiva) necessária para uma relação mais profunda e posterior de envolvimento (avaliação afetiva). A imagem geral - personalidade gastronômica no nosso caso - será condicionada pelo tipo e pela variedade das fontes de informação acessadas.

Conhecer, portanto, a natureza dos canais de comunicação e o tipo de fonte de informação é tarefa relevante para quem deseja entender os processos de formação da imagem gastronômica dos destinos brasileiros e, sobretudo, para os que planejam contribuir para o desenvolvimento turístico das regiões em que operam. São raros os dados acumulados sobre o assunto. As pesquisas realizadas no âmbito do Projeto Caminhos do Sabor - uma iniciativa conjunta da Associação Brasileira de Bares e Restaurantes e do Ministério do Turismo - têm se revelado um precioso esforço para mitigar tal lacuna. O projeto foi concebido para mobilizar o trade turístico dos 65 destinos indutores selecionados pelo MTur visando aumentar a competitividade turística de cada um através de sua gastronomia e de suas tradições culinárias. As ações, que envolvem mobilização das lideranças da localidade, pesquisa das condições de oferta e demanda do setor gastronômico, elaboração do plano de ação para a cidade e qualificação para empresas de alimentação fora do lar - iniciaram-se em 2008 e devem ser concluídas no ano de 2011.

As pesquisas de oferta e demanda foram realizadas em cada cidade que o projeto alcançou e desenhou um quadro detalhado do relacionamento entre turismo e a comida do lugar. Para a análise que apresentamos a seguir, compilamos dados levantados em nove cidades do nordeste brasileiro - Salvador, Aracajú, Maceió, Recife, João Pessoa, Natal, Fortaleza, Teresina e São Luiz, as capitais dos estados que compõem a região - a partir da amostra de turistas. Somando todos os entrevistados totaliza-se um universo de 490 pessoas. A amostra em cada cidade foi determinada em correspondência à amostra de residentes, público que foi igualmente abordado no processo. O cálculo da amostra de residentes baseou-se em dados 
demográficos extraídos do Censo 2000 do Instituto Brasileiro de Geografia e Estatística. A distribuição das entrevistas por cidade pode ser observada na tabela 01, a seguir:

Tabela 01 - Distribuição de Entrevistados por Cidade e Período de Aplicação dos Questionários.

\begin{tabular}{ccccc}
\hline SALVADOR & FORTALEZA & JOÃO PESSOA & RECIFE & SÃO LUÍ́ \\
\hline N 83 & $N 72$ & $N 41$ & $N 65$ & $N 51$ \\
$22-29 / 01 / 2009$ & $7-27 / 8 / 2008$ & $4-22 / 8 / 2008$ & $5-19 / 8 / 2008$ & $15 / 01-19 / 02 / 2010$ \\
\hline ARACAJU & MACEIÓ & NATAL & TERESINA & \\
\hline N 43 & N 49 & N 41 & N 45 & \\
$21 / 8-11 / 9 / 2009$ & $19 / 2-8 / 3 / 2010$ & $5-18 / 8 / 2008$ & $19-30 / 6 / 2009$ & \\
\hline
\end{tabular}

Fonte: elaborado pelos autores com base nos relatórios de pesquisa do Projeto Caminhos do Sabor, 2011.

Dentre as muitas questões abordadas nas pesquisas, pelo menos uma remete diretamente ao tema em análise. Todos os turistas entrevistados foram convidados a indicar quais foram as fontes de informação que lhe levaram a conhecer aspectos da comida da cidade que estava visitando. A pergunta visava identificar as fontes de informação que mais contribuem para a divulgação das culinárias locais. Os resultados agregados para as nove capitais estão representados no gráfico 01 abaixo: 
Gráfico 01-meios de divulgação de informações sobre culinária entre turistas sobre as capitais nordestinas, $\mathrm{n}=490$.

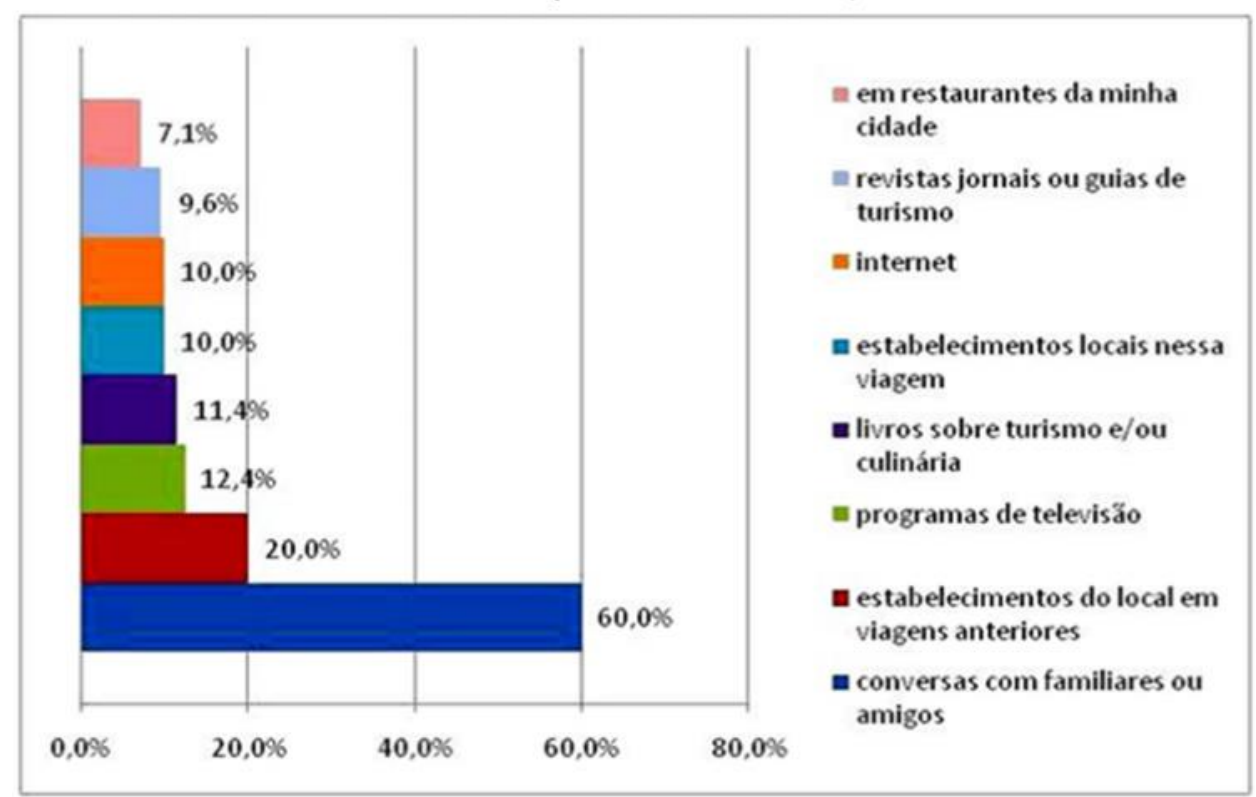

Fonte: Abrasel, Projeto Caminhos do Sabor, 2010.

Os resultados não trazem surpresas. Entretanto, antes de seguir adiante, é conveniente vislumbrar seu contexto. Todas as cidades selecionadas estão, em maior ou menor grau, inseridas na indústria turística brasileira. Em muitos desses destinos, o turismo figura entre as principais atividades econômicas do Estado. Adicionalmente, o nordeste do Brasil é lar de peculiar cozinha regional. A culinária das cidades, em algumas delas, é fortemente vinculada ao território como no caso de Salvador e a culinária baiana. Assim, a região parece madura e adequada para um processo de promoção planejado.

Os dados reunidos no gráfico 1 indicam que o principal meio de circulação de informações sobre a culinária da região é o "boca-a-boca". Não há intermediação nesse caso e as fontes são pessoas próximas, do círculo íntimo do entrevistado. O fenômeno que se convencionou chamar de comunicação "boca-a-boca", assim como o papel que exerce nos processos de consumo, vem sendo sistematicamente estudado desde os anos 1950 (GODES \& MAYZLIN, 2004: GILDIN, 2002). Uma característica em particular desse processo é que ele ocorre numa estrutura que é pouco - ou nada - gerenciável. Em outras palavras, é difícil - do ponto de vista do destino - estabelecer algum nível de controle sobre o conteúdo disseminado. Na maioria 
das vezes, o processo é espontâneo. E, na situação examinada, tende a repercutir as experiências e impressões de fontes que desfrutam de muita credibilidade e poder de influência, já que fazem parte de pessoas de círculos íntimos ou próximos. Ações puramente publicitárias têm pouco poder para diminuir uma impressão ruim que tem origem no fluxo de boca-a-boca. O relato de uma testemunha ou de alguém que é considerado bem informado por seu interlocutor é sempre difícil de ser superado.

A pesquisa coloca os bares e restaurantes do território que foram visitados em viagens anteriores como o segundo mais importante canal da comunicação para a personalidade gastronômica. Vinte por cento dos entrevistados apontaram a alternativa. A distância entre essa opção e a primeira é significativa (40\%). Ainda assim, os estabelecimentos locais se destacam em relação a todas as outras. O resultado nos faz lembrar que os estabelecimentos de alimentação fora do lar não são apenas prestadores de serviço, mas também, agem como importantes relações públicas na promoção da personalidade gastronômica. Essa constatação ganha mais força ao se adicionar à equação os $10 \%$ de entrevistados que selecionaram a alternativa "estabelecimentos locais nessa viagem", que divide com a opção "internet" o quinto lugar no ranking de citações.

Pensar nas características dos dois canais mais citados nos habilita a algumas especulações. Em primeiro lugar, os dois representam lados da mesma moeda e existem em total complementaridade. Parte das informações que circulam no boca-a-boca deve advir das experiências dos amigos e parentes com a comida do lugar. É uma informação em primeira mão e que tem mais valor na formação das expectativas dos entrevistados justamente por ser baseada em fatos (ou quase-fatos) ${ }^{6}$. Seguindo a lógica apontada pela pesquisa, não deve ser pequena a parcela da informação repassada que teve sua origem nos próprios bares e restaurantes do destino, reforçando sua importância como centro irradiador da personalidade gastronômica.

As citações entre o terceiro e quinto lugar na lista (excetuando-se "estabelecimentos do local nessa viagem", já comentada) dizem respeito à contribuição da comunicação mediada no processo de difusão da personalidade gastronômica. As quatro alternativas (programas de

\footnotetext{
${ }^{6}$ Para detalhes de como as expectativas moldam a percepção de consumidores de serviços intangíveis ver Lovelock \& Whrigt (2003).
} 
televisão, livros, internet e revistas) acumularam individualmente volumes de citação nas cercanias dos $11 \%$. Não se trata de um número qualquer. $\mathrm{O}$ volume de citações indica a presença de conteúdos relacionados a culinária das capitais nordestinas nas principais mídias de massa. Essa peculiaridade deve muito à projeção da cultura da região que, em sua literatura, música e dramaturgia, carrega os elementos simbólicos de sua comida. Uma contribuição importante e desejável, porém, o tipo de divulgação espontânea sob a qual se tem pouco ou nenhum controle.

Por fim, a citação menos freqüente - estabelecimentos na minha cidade com pouco mais do que $7 \%$ - revela traços insuspeitos. Em primeiro lugar, sugere que as culinárias locais são pouco representadas nos cidades emissoras. Culinárias regionais prestigiosas ou populares tendem a se tornar especialidades de restaurantes localizados em outros territórios. Veja o caso dos restaurantes franceses ou japoneses, por exemplo. Esses estabelecimentos funcionam como um primeiro contato entre o turista potencial e a outra cultura culinária. Em segundo lugar, indica que se por um lado os restaurantes do lugar visitado são importantes relações públicas para a personalidade gastronômica, os estabelecimentos das cidades de origem do visitante não se prestam como posto avançado e nem exercem papel significativos como divulgadores.

\section{Considerações Finais}

Argumentamos nesse artigo que a culinária e a gastronomia representam recursos valiosos para o reforço da imagem territorial visando o desenvolvimento das atividades turísticas. Sugerimos, também, que para tirar proveito desse potencial é necessário compreender melhor a forma como a informação sobre a comida do lugar circula entre o público-alvo do destino. Para esclarecer essa questão, fizemos a análise de dados empíricos oriundos do Projeto Caminhos do Sabor.

Os dados citados descrevem aspectos interessantes. Em primeiro lugar, os principais canais de comunicação para a personalidade gastronômica seguem sendo os grupos íntimos das pessoas que viajam e os bares e restaurantes do próprio destino. Fica claro, então, que uma variável relevante para a gestão da imagem é a qualidade da experiência a que os turistas são 
submetidos. Problemas de atendimento ou grandes frustrações na prestação de serviços contaminam o fluxo da comunicação boca-a-boca. Por outro lado, informações equivocada ou inadequadas do ponto de vista da proposta de imagem do lugar podem se alastrar com facilidade a partir dos próprios estabelecimentos da região. As autoridades e o trade turístico locais devem compreender a natureza desse problema e se antecipar a ele, usar os bares e restaurantes como veículo de disseminação da informação, capacitando o empresário e o pessoal de atendimento para a tarefa de comunicação, munindo cada ponto de venda de material de divulgação, trabalhando os cardápios para fortalecer a singularidade e autenticidade do território.

Mas é claro que providências desse tipo só podem produzir efeitos caso uma etapa anterior já tenha sido solucionada: o lugar precisa ter construído coletivamente uma proposta de posicionamento para sua comida e ter definido os aspectos fundamentais da personalidade gastronômica que pretende projetar. Se não há algo assim, as informações disseminadas carecem de unidade, aumenta-se o risco de que fatos e dados contraditórios ou desfavoráveis sejam partilhados. Interessante observar que a experiência acumulada no Projeto Cainhos do Sabor não revelou nenhuma cidade, em que pese à importância do tema para o turismo de muitas delas, que tenha definido intencionalmente sua personalidade gastronômica.

Outro aspecto que reforça essa impressão é o menor emprego de outros canais de comunicação - mídia de massa e dirigida - em geral na circulação da personalidade gastronômica. Esse problema repousa, pelo menos parcialmente, na dificuldade de mobilizar os meios de comunicação e outros veículos para a propaganda espontânea de determinados temas. É verdade que em algumas exceções contrastam com a situação da maioria. A presença da comida de Salvador ${ }^{7}$, representada pelo universo da culinária baiana, pode ser percebida em muitos canais diferentes. Mas, também, não é arriscado afirmar que no geral não existe uma política de divulgação da personalidade gastronômica nem, tampouco, os investimentos necessários para tornar a comida do destino conhecida. No geral, e Salvador não é diferente nisso, a projeção das tradições culinárias nos meios de comunicação são reflexos da projeção da própria cultura local que a carrega consigo.

\footnotetext{
${ }^{7}$ Os dados sobre Salvador podem ser encontrados no relatório de pesquisa do Projeto Caminhos do Sabor na cidade.
} 
Futuras investigações podem identificar mudanças nesse quadro e revelar experiências pioneiras na construção e gestão da personalidade gastronômica, da imagem territorial e no desenvolvimento do turismo gastronômico no Brasil.

\section{Referências}

BALOGLU, Seyhmus \& MCCLEARY, Ken W . A Model of Destination Image Formation. Annals of Tourism Research: v. 26, n. 4., pp. 868-897, outubro de 1999.

CHRISTIE, David John. A trilateral model for the management of corporate image: an examination of the inter-relationship between an organization's self image, its projected image and its perceived image. Griffith University: tese (doutorado), 2002.

COELHO NETO, Ernani \& AZEVEDO, Marcelo. Turismo, Imagem Territorial e Gastronomia: o valor simbólico da comida na atratividade de destinos turísticos brasileiros. Revista acadêmica Observatório de Inovação do Turismo, v. V, p. 3, 2010.

CORNER, Dolores M. R. A Gastronomia como Atrativo no Turismo Cultural. Caxias do Sul: V Seminário de Pesquisa em Turismo do Mercosul/III Seminário da ANPTUR - Associação Nacional de Pesquisa e Pós-Graduação em Turismo, 7 e 8 de junho de 2006.

CRISTÓVÃO, Artur, TIBÉRIO, Luís \& ABREU, Sónia. Restauração, Turismo e Valorização de Produtos Agro-alimentares Locais: o Caso do Espaço Transfronteiriço do Douro-Duero. Revista de Turismo e Patrimônio Cultural: v. 6, n. 2, p. 281-290, 2008.

DECAUDIN J.M. La communication marketing: concepts, techniques, strategies. Paris: Economica, 1999.

DÓRIA, Carlos Alberto. A culinária materialista: construção racional do alimento e do prazer gastronômico. São Paulo: Editora SENAC, 2009.

FERNÁNDEZ, Gabriel y AGRELO, Gastón. La Cultura Gastronómica: un factor clave en el diseño de estrategias de imagen urbana - el caso de la ciudad de Bernal. Buenos Aires: Segundas Jornadas de Patrimonio Gastronômico - lo que revelan las cocinas en la mesa gastronomía y turismo cultural, 6 e 7 de agosto, 2003.

GAIO, S. \& GOUVEIA, L. O Branding Territorial: uma abordagem mercadológica à Cidade. Revista A Obra Nasce: Edições UFP, pp 27-36, 2007.

GILDIN, Suzana Z . Understanding the Power of Word-of-Mouth. Revista de Administração Mackenzie: ano 4, n.1, p. 91-106, 2002.

GODES, David e MAYZLIN, Dina. Firm-Created Word-of-Mouth Communication: a fieldbased quasi-experiment. HBS Marketing Research Paper: n. 04-03, julho de 2004.

GRBAC, Bruno \& MILOHANOVIĆ, Ana. Contribution of Food Products in Creating Cultural identity of Tourist Destination. Creta: International Conference on Cultural Heritage And Tourism, p. 83-88, julho de 2008. 
HALL, C. Michael \& SHARPLES, Liz. The Consumption of Experiences or the Experience of Consumption? an introduction to the tourism of taste in HALL, C. Michael et al. (edit.). Food tourism around the world. Amsterdam : Elsevier, p. 1-24, 2003.

KARIM, Shahrim Ab. Culinary tourism as a destination attraction: an empirical examination of the destination's food image and information sources. Oklahoma State University: tese (doutorado), 2006.

KRAUSE, Wendhausen Rodolfo. A gastronomia como fator de influência na escolha de destinações turísticas e de sua hotelaria: base do estudo Balneário Camboriú no ano 2006/2007. Universidade do Vale do Itajaí: tese (doutorado), 2007.

LECLARIE N. Image interne de l'entreprise: concepts, diagnostic. Université de Lille I: tese (doutorado), 1992.

LOVELOCK, Christopher e WRIGHT, Lauren. Serviços: marketing e gestão. São Paulo: Editora Saraiva, 2003.

MITCHELL, Richard \& HALL, C. Michael. Consuming tourists: food tourism consumer behaviour in HALL, C. Michael et al. (edit.). Food tourism around the world. Amsterdam : Elsevier, p. 1-24, 2003.

MURTA, Ivana B. Dultra, SOUZA, Mariana M. Pereira \& CARRIERE, Alexandre de Pádua. Prática Discursivas na Construção de uma Gastronomia Polifônica. Revista de Administração Mackenzie: v. 11, n. 1, jan./fev., 2010.

NEVES, Roberto de Castro. Imagem empresarial: como as organizações (e as pessoas) podem proteger seu maior patrimônio. Rio de Janeiro: Mauad, 2003.

OLIVEIRA, Simão. La Importancia de la Gastronomía en el Turismo: un ejemplo de Mealhada - Portugal. Buenos Aires: Estúdios y Perspectivas em Turismo, vol.16, n.3, p.261-282, jul/set, 2007.

RAND, Gerrie Du, HEATH, Ernie \& ALBERTS, Nic. The Role of Local and Regional Food in Destination Marketing: a South African situation analysis. Journal of Travel \& Tourism Marketing: v. 14, n. 3 e 4, p. 97-112, novembro de 2003.

RASHID, Rosmalina Abdul \& ISMAIL, Hairul Nizam. Critical Analysis On Destination Image Literature. II International Conference on Built Environment in Developing Countries. Kuala Lampur: p. 1812-1827, dezembro de 2008.

RATIER, Michel. L'image en Marketing: cadre théoriqye d'un concept multidimentionnel. Cahier de Recherche du Centre de Recherche en Gestion: n. 152, disponivel em http://w3.univ-tlse1.fr/IAE/files/154_pdf.pdf, 2002.

STANTON, W.J., ETZEL, M.J., e WALKER, B.J. Fundamental of marketing. New York: McGraw-Hill, 1994.

STAW, B. M. e EPSTEIN L. D. What Bandwagons Bring: effect of popular management techniques on corporate performance, reputation, and CIO pay. Administrative Science Quarterly: v. 45, n. 3, pp. 523-556, 2000.

STEINBERGER, Michael. Adeus aos escargots: ascenção e queda da culinária francesa. Rio de Janeiro: Zahar, 2010. 
STILES, Kaelyn, ALTIOK, Özlem \& BELL Michael M.. The Ghosts of Taste: food and the cultural politics of authenticity. Agriculture and Human Values: disponível online, http://www.springerlink.com/index/10.1007/s10460-010-9265-y, março de 2010.

Recebido em: 04/02/2011

Aprovado em: 11/07/2011 